\title{
The Importance of Clusters for the Development of New Industries
}

\author{
Cristina Porumboiu ${ }^{1}$
}

\begin{abstract}
This paper aims to present how new industries have emerged taking advantage of related businesses crowded in specific areas - first, through a review of the current literature on the evolution of industries within clusters; second, through a case study that disseminates the theoretical findings. Undoubtedly, as the findings of previous studies have shown, new industries are increasingly important to the world economy due to their technological power of modernization. Because their potential is as great as their uncertain outlook, it is no surprise that these new industries are growing within clusters, already confirmed in the literature as drivers of competitiveness and economic development.
\end{abstract}

Keywords: clusters, competitive advantage, emerging industries, business networks, life sciences.

JEL Classification: O3, O32, L52

DOI: $10.24818 / \mathrm{REJ} / 2021 / 80 / 05$

\section{Introduction}

From Alfred Marshall to Michael Porter's work, networks of players agglomerated in a specific location and collaborating within a specific business sector raised in importance as drivers for competitiveness and economic development. As the analyses of existing clusters confirmed one by one how the links between actors strengthened location-specific competitive advantage, authorities started to favourise the emerging of new agglomerations. Next, business networks expansion increased internal resilience for economic downturns or other risky situations, on one side, and facilitated the knowledge exchanges between actors, on the other side. This paper aims to review the current literature to highlight how crowded interconnected businesses have facilitated the emergence of new industries and to disseminate theoretical findings in a case study. The growing interest in emerging industries, especially for the European space which is considered less specialized compared to other large markets (European Panorama of Clusters and Industrial Change, 2020), has raised the need to understand how technology transforms traditional means into new competitive products and services. The attention of

${ }^{1}$ Bucharest University of Economic Studies, cristina.porumboiu@yahoo.com

Year XXIV no. 80

June 2021 
research on industrial development in the European Union is focused on ten new industries. Thus, this paper contributes to the current literature with a summary analysis of a case study with the high presence of two important emerging industries (biopharmaceuticals and medical devices), in the country that dominates the top regions with the most cluster stars in emerging industries (Germany). Further on, the current paper may be a point of discussion for future research.

Enclosed in the first section is a review of the current literature regarding clusters' theory. The second part presents the methodological approach. The third part presents the cluster selected, and the last - for findings and conclusions.

\section{Literature review}

Several authors based their research of the new industries on industrial life cycle perspective (Low and Abrahamson, 1997; Phall et al., 2011) and industrial characteristics (Porter, 1980, p.215; Forbes and Kirsch, 2011; Gustafson et al., 2016). Michael Porter (1980) have shared a complex definition of the new industries as "newly formed or re-formed industries that have been created by technological innovations, shifts in relative cost relationships, the emergence of new consumer needs, or other economic and sociological changes that elevate a new product or service to the level of a potentially viable business opportunity." (p. 215). Their importance for the world economy increased due to the technological and environmental solutions provided (European Cluster Observatory, 2012), as they "exploiting a new source of supply of technology, developing a new product, or tapping a new market" (Low and Abrahamson, 1997).

Generally, industries evolve following a "predictable pattern" (Low and Abrahamson, 1997); under three unanimously accepted stages within the speciality literature of industries' lifecycles: emerging, growth and maturity. Only Phall et al. (2011) added two other early stages of industrial evolution before the emerging phase: a "precursor" stage (emergence determined by scientific developments and an" embryonic" stage (scientific developments transposed into technological prototypes).

The emerging stage of industries may be described as "the game without rules" (Porter, 1980 , p. 215), due to lack of information or regulations regarding products and market. However, this uncertainty may represent an excellent opportunity for new firms (Gustafson et al., 2016). At this phase, the industry's competition is low; firms experience slow growth and limited sales; being more focused on innovation than on efficiency (Low and Abrahamson,1997). Nonetheless, the most significant challenges in studying the emerging industries, (Forbes and Kirsch, 2011) remains 
the lack of data for studies and the incapacity to identify these early industries until maturity. The new industries are defined by uncertainty - either technological or strategic (Porter, 1980, p. 216-217). Companies encounter difficulties identifying the most efficient technology to use, amongst the applications available in the market, but simultaneously, insufficient information about competitors, market/industry conditions or customers. However, a turnaround approach can transform the challenges into opportunities sourced by the latest technologies used and a different or new market strategy (Rong et al., 2013).

As the new industries arise when existing players change their business model, by implementing disruptive ideas, according to European Cluster Observatory Report (2012), they tend to agglomerate in areas with location-specific conditions, by establishing linkages with other actors. This "geographically proximate group of interconnected companies and associated institutions in a particular field, linked by commonalities and complementarities" is defined by Michael Porter (1998) as a cluster. Alongside the benefits of networks, companies gain support for dealing with the industry's specific uncertainties (Rong et al., 2013). Porter (1998) point out three advantages of agglomerated companies: (a) productivity - ease of access to qualitative information and technology, advancedskilled employees and suppliers, and more support through coordination with institutions or other related companies.

(b) innovation - the proximity of customers brings more advantages for companies located in clusters than isolated competitors, thanks to rapid ideas-to-market transfers.

(c) new business formation - the linkages created between clusters' members. Market opportunities are immediately seized upon in such agglomerations, and new businesses arise taking advantages of new needs, lower entry barriers, and resources already available.

By combining the potential of clusters as "driving force in increasing exports and magnets for attracting foreign investments" (Porter, 1998) with the power of emerging industries as a boost of industrial competitiveness and "the growth and employment of the future" ( European Commission, 2014), governments have in these structures a proper solution for economic development. The authorities can facilitate agglomerations' development through cluster policies, oriented towards "intensifying the use of knowledge in traditionally strong clusters" (Ketels and Memedovic, 2008). 


\section{Methodology}

The second part of this paper aims to bring evidence on how an emerging industry evolved under clusters' advantages. As a research method, a case study built on publicly available data brings an in-depth perspective of how clusters' business network favoured some industries' emergence. Two features of clusters' analysis make case study the best instrument for this research: (a) it will bring more evidence over the type of networks existing within the analysed cluster, which currently is not possible measurable using quantitative instruments, and (b) it will bring specific competitive insights of clusters by mapping its actors and analysing them, as pointed out by Porter in his case study of the Californian wine (1998, pg 221).

Life sciences subsectors such as biotechnologies, biopharmaceuticals and medical devices are some of the most important emerging industries, (Ketels and Protsiv, 2014), the last two ones already under the spotlight of European industrial research since 2014. Their highly innovative solutions are critically upgrading life quality. In the United States, life sciences can become "the largest industry in the world" (Enriquez and Goldenberg, 2002); thus, the authorities started to finance them since the early 1990s. The European Union began to encourage these industries since 2002.

The country selected for the case study was considered based on top countries with performing clusters in emerging industries (European Panorama of Clusters and Industrial Change, 2019) - Germany. Despite Berlin is well-known for the agglomerations of creative industries, it is also the region with the high-performing biopharmaceutical clusters and medium-performing medical devices clusters, based on European Panorama of Clusters and Industrial Change (2020), measured by the intensity of cluster's size, specialization, productivity, SMEs performance and innovation leaders.

Development of biopharmaceuticals and medical devices emerging industries in Berlin-Brandenburg

In terms of historical context, despite the back and forths battles for a centralised state, Germany is one of the leading global powers in international trade thirty years after its unification, being the 3rd largest importer and exporter in 2018. One of the most exported industry, the pharmaceuticals, has historical roots in the abundance of coal, back in the $19^{\text {th }}$ century. The coal-tar, "the waste material left when coal is transformed into coke " was an essential resource as under some processes of distillation "provided many organic chemicals [...] used in the synthesis of new medicines" (Ravina,2011, 
pg 23). Later on, the evolution of drugs facilitated Germany's industrial development due to companies' close network with academic institutions (Ravina, 2011, pg 23).

Germany quickly embraced during the beginning of ' 90 s the increasing popularity of "clusters" (Vicente, 2018, pg.2) as "vebicles to bridge the perceived gap between science and industry to accelerate innovation" (Kiese, 2013). Consequently, Germany initiated between 1993 to 2012, more than 17 national cluster initiatives and 16 initiatives at the federal state level, the first one oriented to the biotechnology industry. The US and the UK had already shown the effects of biotech clusters for national competitive advantage (Kiese,2013). However, Germany had a guarantee for success in the low government involvement (Dohse, 1998), plus the disadvantage of federalism, which was a better direction for approaching initiatives for clusters (Kiese, 2013). Alongside with the low cluster initiatives and its involvement, the government started to hugely fund the research activities, especially the life sciences, starting in 1973 with the Proteom Research Program, it supported 914 supported companies for more than 30 years (Fier and Heneric, 2005). Other ten programs were financed by the local authorities, before the first initiative towards clusters' creation organised by the Federal Ministry for Education, Science, Research and Technology (BMBF) with the purpose of "stimulating biotech firm start-ups, the growth of existing companies and the provisions of venture capital" (Dohse, 1998). The first cluster initiative - BioRegio Contest, was launched in 1995 with 17 regions participating, while the follow-on initiative - BioProfile contest, was organised in 1999, with 30 regional groups registered (Engel et al., 2011).

The cluster's network located in the German capital city, currently known as HealthCapital, had as catalyst for all of today's existing links within the region the leading university clinic in Europe - Charité, established in 1710 to serve the plague victims around Berlin. One century later, it becomes the home of the medical faculty of the University of Berlin(Charite, 2016;). Scientific research from Berlin started to be worldwide known in late 1880 due to Robert Koch's discoveries on bacteria as sources for infections (Robert Koch Institute, 2020). Later on, he became the head of the Royal Prussian Institute for Infectious Diseases, one of the world's oldest biomedical institutes, founded in 1891 and located in Berlin-Mitte area.

Next century, the establishment of research institutes was considered a direction for increasing Germany's science advantage. Thus, the Kaiser Wilhelm II established in 1911 the Kaiser Wilhelm Society's foundation, in Berlin. During the following four years, Berlin-Dahlem area became the first research campus of Germany (Max 
Planck Society, 2020), with the Institute of Chemistry (1912), the Institute of Experimental Therapy and Biochemistry (1913) and the Institute for Biology (1915). Alongside with the hospital's development and establishment of Berlin University, the nineteen century was also the time of some big companies' foundation - the establishment of Bayer or Boehringer Ingelheim in West Germany, of Belin pharmaceutical companies Schering AG and Berlin-Chemie, or Merck's national expansion.

Despite the unfavourable political situation of Berlin after World War II until the country's unification back in 1990, the city remained an essential medical research point for its universities and institutes. The business environment poorly counted only 15 biotech companies in 1990 (Nature, 2000), constrained by limited financing of medical research after the WWII; venture capitalists did not exist, and the potential of research ideas did not attract banks. Moreover, since the interbelic period, several researchers left the German laboratories due to the political situation and continued their research mostly in the United States. Plus, the legislation restricted companies' possibility for being listed on the stock exchange (the first German biotech company - Qiagen moved to the Netherlands for its IPO) or production of biotechnologies (Hoechst set-up a plant for the production of recombinant insulin in 1996 after 12 years of legal disputes with the local authorities) (Hamman, 2002).

Cooperation for innovative technologies started within the Berlin-Brandeburg since 1992, with a contest for high tech products, including medical technology and biotechnology. Three years later, the regional initiative attended BioRegio, without receiving governmental financing. However, Germany started to participate in the international research of the human genome alongside other countries (Hamman, 2002), with two allocated centres - one in Berlin (Max Planck Institute for Molecular Genetics) and another one in Heidelberg (German Cancer Research Center). Nonetheless, both federal states improved their regional cooperation and established in 1998 BioTop Berlin-Brandenburg action centre (Berlin-Brandenburg, 2000). One year later, Berlin-Brandenburg was selected one of the three clusters winners of BioProfile Contest, with a public funding horizon 2001-2007 (Engel et al., 2011).

By 2019, the cluster organization established in 2010 to manage the network of life sciences companies, universities and research institutions, investors and authorities, counted on 11 large life sciences specialized universities and 24 research institutes, a network of 12 large life companies, plus around 600 SMEs companies (332 
medtech, 225 biotech and 34 pharma) and more than 130 hospitals and 70 rehabilitation centres. Around the network of academia and business, investors such as large and regional banks, more than 60 accelerators and incubators - out of which seven are oriented explicitly to the life sciences industry, venture capital and private equity firms and other regional venture investors as are part of the cluster's ecosystem.

Based on the evolution of the agglomeration of academia, businesses, authorities and investors existing in the Berlin region specialized or related to the life sciences traditional industries, the emerging industries of biopharmaceuticals and medical devices had benefit of the following advantages:

- Access to high quality knowledge and linkages within the leading industrial center of Germany - as a 2012 report of the cluster organization mentioned that in 2011 the Berlin-Brandenbourg region leg the national biotech industry, overpassing Munchen and Heidelbelberg clusters, historically advanced in research activities.

- Access to high-skilled personnel - around 380,000 employees were working in the life sciences companies in 2018, counting $12 \%$ of the total employment of Berlin-Brandenburg workforce (Eurostat ${ }^{2}$ ).

- Ease of business creation and development of early industry - as promoted by the cluster organization, yearly, new 50 innovative start-ups are established in the fields of biotech, medtech or pharma.

- Access to potential beneficiaries of newly innovative products within the network of more than 130 hospitals and care centers.

- Access to high technology which may shift traditional medicine, in new directs such as molecular diagnostics, bioanalysis, therapeutics and regenerative medicine, bioinformatics.

- Access to funding for initial costs from the large network of banks, incubators and other private investors part of the cluster.

\section{Conclusions}

This study confirmed, based on the evidence of one strong cluster, the importance of networks and abundance of actors for the evolution of new industries. Besides the large country history in life sciences research the area of Berlin-Brandenburg had the advantage of having a high density of hospitals (the place where research starts, where solutions are tested and ultimately where discoveries arise). As the

${ }^{2}$ https://ec.europa.eu/eurostat/databrowser/view/lfst_r_lfe2emp/default/table?lang=en

Year XXIV no. 80

June 2021 
evidence collected for this case study shows, agglomerations of companies alongside hospitals and universities hosted the arising of new industries even before the local authorities recognised the economic potential. Historical research on life sciences issues started a century ago in the Berlin area was upgraded by the new technologies. Moreover, such agglomerations of knowledge institutions located in different regions may raise the competitiveness within the country and its national competitive advantage. Thus, the capital city cluster benefits from the most agglomerated network of such institutions within the region and it becomes the most advantageous places for the rise of new industries.

In the end, this study has several limits, which may be starting points for future research: only one cluster analysed, located in a specific location and a specific development stage, specificity of type and strength of network developed within the cluster, and missing expertise of clusters' members on the value-added of links created within agglomeration and which favoured emerging industries. Moreover, the current infrastructure of the European Union is not as updated as the American cluster tool in order to capture the evolution of the emerging industries within the agglomerations. Therefore, there remains a place for analysing if the success of biopharmaceuticals and medical devices emerging industries in the German region Berlin-Brandenburg was or can be replicated in different locations - inside or outside a network of academia, business and authorities.

\section{References}

Andersson, T., Serger, S. S., Sörvik, J., \& Hansson, E. W. (2004). The Cluster Policies Whitebook. Malmö: International Organisation for Knowledge Economy and Enterprise Development.

Belussi, F., \& Caldari, K. (2008). At the origin of the industrial district: Alfred Marshall and the Cambridge school. Cambridge Journal of Economics, 33(2), 335-355.

BioTOP. (2010, April). BioTOP Report 2010. Journal of Biotechnology in BerlinBrandenburg(40).

BioTOP. (2012). BioTOP Report 2012 - Biotechnology in Berlin-Brandenburg. Berlin: BioTOP Berlin-Brandenburg.

Birch, K. (2017). Innovation, Regional Development and the Life Sciences (I ed.). New York: Taylor \& Francis Group.

Bjørgum, Ø. (2016). MNCs entering an emerging industry: The choice of governance mode under high uncertainty. Cogent Business \& Management, 3(1). doi:10.1080/23311975.2016.1258135 
Buciuni, G., \& Pisano, G. P. (2015). Can Marshall's Clusters Survive Globalization? Harvard Business School - Working Paper 15-088.

Charité - Universitätsmedizin Berlin . (2016). People Teaching Research. Berlin: Corporate Communication · Charité — Universitätsmedizin Berlin .

Cooke, P. (2001). New economy innovation systems: biotechnology in Europe and the USA. Industry and Innovation, 8(3), 267-289.

Delgado, M., Porter, M. E., \& Stern, S. (2015). The Resilience of Clusters: Evidence from the Great Recession. DRUID Conference. Rome.

Dohse, D. (1998). The BioRegio-contest: a new approach to technology policy and its regional consequences. Kiel Working Paper(880).

Engel, D., Mitze, T., Patuelli, R., \& Reinkowski, J. (2011). Does the Support of Innovative Clusters. Quaderni - Working Paper DSE(744).

Enriquez, J., \& Goldberg, R. A. (2000). Transforming Life, Transforming Business: The Life-Science Revolution. Harvard Business Review, 78(2), 96-96.

European Cluster Observatory. (2012). Cluster-specific framework conditions for world-class clusters in emerging industries. Brussels. Retrieved from https://ec.europa.eu/docsroom/documents/16266/attachments/1/transl ations/en/renditions/native

European Cluster Observatory. (2014). European Cluster Panorama 2014. European Comission, Brussels. Retrieved from http://ec.europa.eu/ DocsRoom/documents/7242/attachments/1/translations/en/renditions $/ \mathrm{pdf}$

European Cluster Observatory. (2016). European Cluster Panorama 2016. European Cluster Observatory, Brussels. Retrieved from http:/ /ec.europa.eu/DocsRoom/documents/20381

European Comission. (2002). Life sciences and biotechnologies - A Strategy for Europe. Brussels.

European Comission. (2014). Horizon 2020 - Monitoring Report 2014. Brussels. doi:doi 10.2777/32

European Panorama of Clusters and Industrial Change. (2019). Emerging industries: Driving strength in 10 cross-sectoral industries. Brussels: European Comission. Retrieved from https://ec.europa.eu/ growth/content/trends-european-clusters-results-2019-europeanpanorama-trends-and-priority-sectors-reports_en

European Panorama of Clusters and Industrial Change. (2020). Performance of strong clusters across 51 sectors and the role of firm size in driving specialisation. 2020: European Comission. Retrieved from https://ec.europa.eu/docsroom/documents/40524 
Fier, A., \& Heneric, O. (2005). Public R\&D Policy: The Right Turns of the Wrong. ZEW Discussion Papers(5-6).

Forbes, D. P., \& Kirsch, D. A. (2011). The study of emerging industries: Recognizing and responding to some central problems. Journal of Business Venturing(26), 589-602. doi:10.1016/j.jbusvent.2010.01.004

Gustafsson, R., J“a”askel“ainen, M., Maula, M., \& Uotila, J. (2016). Emergence of Industries: A Review and Future Directions. International Journal of Management Reviews(18), 28-50. doi:DOI: 10.1111/ijmr.12057

Hammar, F. (2002). History of Modern Generics in Germany. In T. Scheper, History and Trends in Bioprocessing and Biotransformation (Vol. Advances in Biochemical Engineering/Biotechnology). Springer.

Horii, R. (2011). Wants and past knowledge: Growth cycles with emerging industries. Journal of Economic Dynamics \& Control(36), 220-238. doi:10.1016/j.jedc.2011.08.001

Humboldt-Universität Zu Berlin. (2020). Humboldt-Universität Zu Berlin History. Retrieved 04 01, 2020, from https://www.hu-berlin.de/en/ about/history/huben_html

Jacobs, D., \& Man, A.-P. D. (1996). Clusters, industrial policy and firm strategy. Technology Analysis \& Strategic Management, 8(4), 425-438. doi:10.1080/09537329608522461

Jong, S. (2006). How organizational structures in science shape spin-off firms: the biochemistry departments of Berkeley, Stanford, and UCSF and the birth of the biotech industry. Industrial and Corporate Change, 15(2), 251-283. doi:10.1093/icc/dtj014

Ketels, C. H., \& Memedovic, O. (2008). From clusters to cluster-based economic development. International Journal of Technological Learning, Innovation and Development, 1(3), 375-392.

Kiese, M. (2013). Regional Cluster Policies in Germany - A Multi-Level Governance Perspective on Policy Learning. European Review of Industrial Economics and Politics(5).

Kleyn, D., Kitney, R., \& Atun, R. A. (2007). Partnership And Innovation In The Life Sciences. International Journal of Innovation Management, 11(2).

Low, M. B., \& Abrahamson, E. (1997). Movements, bandwagons and clones, industry evolution and the entrepreneurial process. Journal of Business Venturing(12), 435-457.

Marshall, A. (1890). Principles of Economics (1st ed.). London: Macmillan.

Max Planck Society. (2020). History of the Kaiser Wilhelm Society (KWS). Retrieved 04 01, 2020, from https://www.mpg.de/10424011 /History_of_the_Kaiser_Wilhelm_Society.pdf 
Nature. (2000, 08 20). Spotlight on Berlin-Brandenburg. doi: https:// doi.org/10.1038/nj0012

Phall, R., O'Sullivan, E., Routley, M., Ford, S., \& Probert, D. (2011). A framework for mapping industrial emergence. Technological Forecasting \& Social Change(78), 217-230. doi:10.1016/j.techfore.2010.06.018

Porter, M. E. (1980). Competitive strategy: techniques for analyzing industries and competitors. New York: Free Press.

Porter, M. E. (1990). The Competitive Advantage of Nations. New York: Free Press.

Porter, M. E. (1998). Clusters and Competition, New Agendas for Companies, Governments and Institutions. In M. E. Porter, On Competition. Harvard Business School Press.

Porter, M. E. (2003). The Economic Performance of Regions. Regional Studies, 37(6-7), 549-578. doi:10.1080/0034340032000108688

Ravina, E. (2011). The Evolution of Drug Discovery: From Traditional Medicines to Modern Drugs. Weinheim, Germany: Wiley-VCH Verlag GmbH \& Co. KGaA.

Rong, K., Shi, Y., \& Yu, J. (2013). Nurturing business ecosystems to deal with industry uncertainties. Industrial Management \& Data Systems, 113(3), 385 - 402. doi:http://dx.doi.org/10.1108/02635571311312677

Vicente, J. (2018). Economics of Clusters: A Brief History of Cluster Theories and Policy. Springer.

World Bank. (2019). Doing Business 2019. Washington.

World Economic Forum. (2019). The Global Competitiveness Index . Geneva.

World Trade Organization. (2018). Trade Profiles 2018. Geneva. 